\title{
DIETARY FAT AND PLASMA LIPIDS
}

\author{
M. I. GURR ${ }^{1,3}$, NAZELI BORLAK ${ }^{2}$ AND SMITA GANATRA \\ ${ }^{1}$ Milk Marketing Board, Thames Ditton, Surrey KT7 0EL, ${ }^{2}$ Department of \\ Biochemistry \& Physiology and ${ }^{3}$ Department of Food Science \& Technology, \\ University of Reading, Reading RG6 2AP
}

\section{CONTENTS}

INTRODUCTION: WHY ANOTHER REVIEW? . . . . . . . . 63

DIETARY LIPIDS AND THEIR METABOLISM . . . . . . . . 64 CONTRIBUTION OF LIPIDS TO THE DIET . . . . . . . . . . . . 64

METABOLISM OF LIPIDS.

RELATIONSHIPS BETWEEN DIETARY LIPIDS AND BLOOD LIPIDS . $\quad 67$

EARLY WORK . . . . . . . . . . . . . . . . . . . . $\quad$. 67

INFLUENCE OF DIETARY CHOLESTEROL . . . . . . . . . . . 67

DIETARY SATURATED AND POLYUNSATURATED FATTY ACIDS . . . 69

MONOUNSATURATED FATTY ACIDS . . . . . . . . . . . 72

INFLUENCE OF TRIACYLGLYCEROL STRUCTURE • . . . . . . . . 75

EXPERIMENTAL DESIGN AND PROBLEMS OF INTERPRETATION . . . 75

PRACTICAL AS DISTINCT FROM EXPERIMENTAL DIETS . . . . . 78

Habitual diet and blood lipoprotein concentrations . . . . . . . . . . . $\quad$. 78

Influence of modifying dietary fat on blood lipoprotein concentrations . . . . 79

CONCLUSION . . . . . . . . . . . . . . . . . . . . . 80

REFERENCES . . . . . . . . . . . . . . . . . 81

\section{INTRODUCTION: WHY ANOTHER REVIEW?}

It is difficult to be unaware now of the prevailing mood that in choosing one's diet one had best do one's utmost to avoid fatty foods. This applies not only to those trained in nutrition (O'Hara-May, 1987) but also to the shopper in the supermarket who receives information from the news media, the general practitioner, the food manufacturer and the retailer (Freckleton, 1986). There may be several reasons for this, among them the wish to lose, or at least not to gain, weight but principally a desire to avoid cardiovascular disease (CVD) (Department of Health and Social Security, 1984). In 1984, CVD was the certified cause of $40 \%$ of deaths in men and $38 \%$ of deaths in women in the UK. Most deaths from CVD occur in old age, the median age of death in 1984 having been 74 years for CVD and 79 years for stroke. Nevertheless, 30000 CVD deaths occurred in men under the age of 65 years.

The science behind the current mood that some modifications of dietary fat are needed by the population in general has had a long and complex evolution. Many of those who are directly involved in nutrition policy, or nutritionists watching with interest from the sidelines but without a background in lipid biochemistry and nutrition, are probably unaware of this evolution. Familiar dietary guidelines, such as those of the Department of 
Health and Social Security (1984) and many others, are based largely, but not wholly, on an assumption of the validity of the 'lipid hypothesis'. This phrase is frequently used but a survey of writings on the subject soon reveals that different authors have used the term in different ways. Our use of the term proposes that the amount and type of dietary fat (in particular, some types of saturated fatty acids) are important factors leading to an elevated plasma cholesterol concentration (primarily low-density lipoprotein (LDL)-cholesterol) which in turn is a causal factor in the development of atherosclerotic disease. Moreover, the complete hypothesis incorporates the proposition that reduction in plasma LDL can be achieved by modifying dietary fat and that this will decrease the risk of CVD. The complete hypothesis can be regarded as being constituted of four distinct but related tenets:

(1) high dietary intake of fat-especially saturated fatty acids-leads to a high concentration of plasma cholesterol (especially LDL);

(2) high plasma cholesterol concentration leads to high CVD mortality;

(3) reducing the dietary intake of fat - especially saturated fatty acids - leads to a lower concentration of plasma cholesterol (especially LDL);

(4) reducing plasma cholesterol concentration (LDL) leads to lower CVD morbidity and mortality.

In categorizing the hypothesis in this way, it is easy to give the impression of rather simple relationships. This is not so. The scheme as shown gives no hint of the complex relationships between blood lipids and total dietary fat, saturated, monounsaturated and polyunsaturated (PUFA) fatty acids or dietary cholesterol. It does not consider whether it is the absolute intake of these dietary components that is important or the ratio between the different fat components or between fat and other energy-providing constituents of the diet. Neither does it make distinctions between the types of plasma lipoproteins of which cholesterol is a constituent.

Our review focuses specifically on that part of the 'lipid hypothesis' that is concerned with the relationships between dietary lipids and the concentrations of lipids circulating in the blood (tenets 1 and 3 in the previously stated sequence). We shall discuss the development of the concept that dietary fat is a primary determinant of plasma lipids, and the strengths and limitations of the experimental evidence, to allow the reader to get the current debate more in perspective. Before we do this, it will be appropriate briefly to examine the contribution of lipids in the diet at the present time. We will focus primarily on the UK but will set this country in an international perspective. This will lead on to a brief exposition of the basics of lipid metabolism so that the general reader can follow the main arguments in the following sections. The reader is referred to Gurr \& James (1980) and Vance \& Vance (1985) for a detailed treatment.

\section{DIETARY LIPIDS AND THEIR METABOLISM}

\section{CONTRIBUTION OF LIPIDS TO THE DIET}

According to the National Food Survey (Ministry of Agriculture, Fisheries and Food, 1987), fat in the present UK diet provides on average $42 \%$ of total energy intake. The contributions made by various fatty acids to the total diet have been changing over the last few years (see table 4.4 of Ministry of Agriculture, Fisheries and Food, 1987). There has been a decrease in the intake of saturated fatty acids and an increase in PUFA resulting in an increase in the polyunsaturated to saturated fatty acid ratio $(P: S)$ from $0 \cdot 25$ in 1981 to 0.36 in 1987.

The major sources of fat in the UK diet are now: spreading fats and cooking fats and oils $(34 \%)$; meats $(26 \%)$; milk, cream and cheese $(18 \%)$; eggs $(2 \%)$ and fish $(2 \%)$. 
Quantitatively, the most important dietary lipids are triacylglycerols, which account for about $90 \mathrm{~g} / \mathrm{d}$. Phospholipids provide about $4-8 \mathrm{~g} / \mathrm{d}$, glycolipids $1 \mathrm{~g} / \mathrm{d}$ and cholesterol $350-450 \mathrm{mg} / \mathrm{d}$. Of the fatty acids, saturated fatty acids account for $51 \%$ of the total, monounsaturated $35 \%$ and polyunsaturated $14 \%$. The contribution of fatty acids with transunsaturation is estimated to be about $7 \mathrm{~g}$ /person per day (Gurr, 1988).

During the 1980s, the consumption of lipids has been slowly declining, although the proportion of energy provided by fat has remained remarkably constant (see table 4.3. Ministry of Agriculture, Fisheries and Food, 1987): The reason for this is unclear and one can only speculate that a diet containing a smaller proportion of fat is found to be unacceptable by many people.

There are wide differences between 'developed' countries in the amounts and types of fat consumed. Thus, according to Food and Agriculture Organization (1986) the amount of fat available in the food supply varies ( $\mathrm{g} /$ person per day; $\%$ animal shown in parentheses): Japan, 83 (45); Finland 132 (80); Australia, 137 (62); Italy, 139 (50); UK 143 (68), USA 167 (59), Denmark 174 (78), The Netherlands 179 (71). Values from different countries and different sources, however, have to be interpreted with caution. Values for the amount of fat available from the food supply, quoted previously, are useful in making international comparisons. They have the disadvantage that they overestimate intakes as they do not account for wastage. They do, however, provide a reliable basis for the assessment of longterm trends in, and shares of, nutrient supplies in all food sources for both at-home and out-of-home consumption. The National Food Survey in the UK (Ministry of Agriculture, Fisheries and Food, 1987), discussed previously, gives more detail about different foods and nutrients but measures only food supplies bought for home consumption. Other methods for studying the fat intakes of individuals, e.g. dietary recall or weighed intakes, also have their limitations (Marr, 1981; Bingham, 1987).

\section{METABOLISM OF LIPIDS}

Fatty acid esters in food (mainly triacylglycerols, phospholipids and cholesteryl esters) need to be hydrolysed in the gastrointestinal tract before efficient absorption can take place (Carey et al. 1983). As digestion progresses, the oil phase decreases in volume and the products of digestion pass into mixed micelles: large molecular aggregates consisting of monoacylglycerols, long chain fatty acids, bile salts and I-monoacyl-phosphoglycerides. The mixed micelles are able to draw into the hydrophobic core the less-water-soluble molecules such as cholesterol, carotenoids, tocopherols and some undigested triacylglycerols.

Lipid absorption occurs mainly in the jejunum. Rapid re-esterification of triacylglycerols from monoacylglycerols and long chain fatty acids and of phosphoglycerides from 1monoacylphosphoglycerides and long chain fatty acids occurs in the enterocytes. Fatty acids with chain lengths shorter than twelve carbon atoms are absorbed directly into the portal blood, metabolized by the liver and do not contribute to plasma lipids or adipose tissue stores. Cholesterol absorption (see Grundy, 1983) is completed by re-esterification catalysed by acyl-CoA: cholesterol acyltransferase $(E C 2.3 .1 .26)$ or by reversal of cholesterol esterase ( $E C$ 3 1 1 1 13). The former enzyme is induced by large concentrations of dietary cholesterol (Tso, 1985).

Triacylglycerols resynthesized in the enterocyte acquire a stabilizing coat of phospholipids and apolipoproteins (apoA and apoB). These large spherical particles termed 'chylomicrons' are secreted into the lymphatic vessels and pass via the thoracic duct to the jugular vein. Chylomicrons represent one extreme of a range of molecular aggregates of lipids and proteins, termed lipoproteins, whose role is to transport lipids between tissues via 
the blood. The protein moieties ('apolipoproteins') not only help to stabilize the lipid particles in their aqueous environment but also provide a means whereby lipoproteins are 'recognized' by tissues and their metabolism directed and controlled (Goldstein \& Brown, 1977; Albers \& Segrest, 1986; Havel, 1980, 1986).

About half the chylomicron triacylglycerols are hydrolysed in 2-3 $\mathrm{min}$ by lipoprotein lipases in the capillaries of the muscles, mammary gland or adipose tissues but the particles are not completely degraded. 'Remnant' particles with proportionately less triacylglycerol and more cholesterol are taken up by the liver where the cholesterol is used for membrane or new lipoprotein biosynthesis, or converted into bile acids. If the diet contains an appreciable amount of fat, endogenous lipid biosynthesis is repressed, although a low level of turnover is occurring at all times. When carbohydrate is the primary source of dietary energy, the liver synthesizes lipids which are exported into the blood as 'very-low density lipoproteins ' (VLDL), particles similar to chylomicrons but smaller, denser and containing relatively more phospholipids, cholesterol and protein. VLDL are degraded by a mechanism similar to that described for chylomicrons. The VLDL 'remnant' is usually termed an 'intermediate density lipoprotein' (IDL) since further degradation yields particles of LDL.

LDL are the major carriers of plasma cholesterol in man, so that in a person having a plasma cholesterol concentration of $5 \mathrm{~mm}$, about $70 \%$ is carried on LDL. The particles comprise $25 \%$ protein and $75 \%$ lipid, of which cholesterol contributes $60 \%$, four-fifths of which is cholesteryl ester, mainly esterified with $18: 2,18: 1$ and 16:0 fatty acids. Their role is to deliver cholesterol to tissues for membrane synthesis. Discharge of cholesterol can occur by passive endocytosis or, more efficiently, by a specific receptor-mediated uptake mechanism (Goldstein \& Brown, 1977, 1984; Havel, 1986) in which the receptor 'recognizes' the apoB component of LDL and binds to it. The LDL-receptor complex is taken up into the cell and the LDL is degraded by lysosomal enzymes. The liberated unesterified cholesterol interacts with the endoplasmic reticulum on which are located the enzymes of cholesterol biosynthesis and inhibits hydroxymethylglutaryl-CoA reductase (EC 1.1.1.88; HMG-CoA reductase), the rate-limiting enzyme in the sequence. Familial hypercholesterolaemia, an inherited disorder characterized by high circulating concentrations of LDL, results from an absence of or defect in the LDL receptor.

Chemical modification of certain amino acid residues of apolipoproteins, either artificially or in vivo (e.g. as a result of lipid peroxidation) results in loss of recognition by the normal LDL receptor. Modified LDL can, however, be recognized by so-called 'scavenger receptors' on macrophages (Brown \& Goldstein, 1983).

The remaining important class of plasma lipoproteins is the high density lipoprotein class (HDL), now thought to be involved in scavenging unesterified cholesterol where it may have accumulated in lipoprotein particles or cell membranes, and transferring it to the liver for further degradation, for example, to bile acids. This process is now generally termed 'reverse cholesterol transport'. A key step involves the enzyme lecithin-cholesterol acyltransferase (EC 2.3.1.43; LCAT) which is a component of HDL and catalyses the transfer of a fatty acid from phosphatidylcholine in HDL to cholesterol to form a cholesteryl ester (Roheim, 1986). Molecules of the substrate (cholesterol) and product (cholesteryl ester) readily exchange between plasma lipoproteins and between lipoproteins and cell membranes, an exchange that is facilitated by transfer proteins (Tall, 1986). The cholesteryl esters are transported to the liver in lipoproteins that contain apoB or apoE, thereby completing the process of reverse cholesterol transport.

In Western man, whose diet generally contains a high proportion of energy as fat, the enzymes of fat biosynthesis (even though present in many tissues, the most important of which is the liver) are probably switched off and the needs for both storage and structural 
fats are satisfied from dietary intake. Turnover of lipids, however, continues in all tissue at a low level of enzymic activity.

Diet may control fatty acid synthesis by influencing the synthesis of the enzymes of fatty acid biosynthesis or their activity, through the availability of cofactors, such as pantothenic acid and biotin, or by influencing the concentrations of circulating hormones that induce or suppress the synthesis of some enzymes of lipid metabolism (Gurr \& James, 1980). Virtually all tissues contain enzymes (desaturases) that catalyse the introduction of double bonds into saturated fatty acids to form monounsaturated fatty acids, of which oleic acid is quantitatively the most important. Further desaturation of oleic acid or dietary linoleic and $\alpha$-linolenic acid produces polyunsaturated fatty acids belonging to the three main families: $n-9, n-6$ and $n-3$, respectively (Sanders, 1988). Normally the $n-6$ pathway from linoleic acid to arachidonic acid predominates but elevating the proportion of dietary $n-9$ or $n-3$ fatty acids can influence the balance between the long chain fatty acid end-products of these pathways or the spectrum of eicosanoids formed from them (Needleman et al. 1986; Sanders, 1988). These changing patterns can affect the properties of cell membranes and thus the activity of cell surface receptors (McMurchie, 1988), modifications that may be relevant to the changes in blood lipoproteins to be described later.

The inclusion of cholesterol in the diet decreases the rate of cholesterol biosynthesis in the liver and probably other tissues through the inhibition of HMG-CoA reductase (Goldstein \& Brown, 1984). The human body may synthesize about 500-1000 mg cholesterol/d compared with $250-750 \mathrm{mg}$ entering from the diet daily, of which the net absorption may be about $50 \%$. Thus the average body synthesizes about two to four times as much cholesterol as is taken in from the diet to satisfy the demands for membrane, bile acid and steroid hormone synthesis.

Body lipids are stored mainly in adipose tissue in which the pool of esterified fatty acids undergoes continuous, though slow, turnover (Gurr, 1988). The half-life of linoleic acid (which must originate from the diet) has been estimated at between 350 and $750 \mathrm{~d}$ (Hirsch et al. 1960). Fatty acid composition of human adipose tissue biopsy samples has been used as a tool in epidemiological studies to indicate long-term fatty acid intakes of individuals, since estimates by dietary surveys contain a large random error (Katan et al. 1986).

\section{RELATIONSHIPS BETWEEN DIETARY LIPIDS AND BLOOD LIPIDS}

\section{EARLY WORK}

Although we can find publications as early as the nineteenth century, it was not until the early 1950 s that wide interest in the effects of different fats on plasma cholesterol began. Much of this earlier work is reviewed by McGandy \& Hegsted (1975) but the interested reader is encouraged to go back to some of the original classical papers, especially Groen et al. (1952), Kinsell et al. (1952), Ahrens et al. (1957), Keys et al. (1957) and Hegsted et al. (1957, 1965). For more recent reviews, see Goldberg \& Schonfeld (1985) and McNamara (1987).

\section{INFLUENCE OF DIETARY CHOLESTEROL}

Addition of cholesterol to the diets of many species of experimental animals elicits a rise in plasma cholesterol concentration. Rabbits are particularly sensitive (e.g. Moore \& Williams, 1966; Van Zutphen \& Fox, 1977; Beynen et al. 1987) and so are many types of monkeys (e.g. Eggen, 1976; Beynen et al. 1987). Rats are relatively insensitive and to measure an effect it has usually been necessary to add extreme amounts of cholesterol to 
the diet in combination with the bile acid, cholic acid, which may assist by enhancing the absorption of the cholesterol (Beynen et al. 1987).

There has been, and still is, controversy about the question of whether cholesterol in the diet of man has a significant influence on the concentration in the plasma. Keys et al. (1957) initially rejected a role for dietary cholesterol in the regulation of plasma cholesterol, but later included a term of dietary cholesterol in a revised equation:

$$
\Delta \text { cholesterol }=2.7 \Delta S-1.35 \Delta P+1.5 \Delta Z,
$$

where $S$ and $P$ are percentages of total energy provided (mainly in triacylglycerols) by saturated and polyunsaturated fatty acids respectively and $Z$ is expressed as $\mathrm{mg}$ cholesterol $/ 4280 \mathrm{~kJ}$.

Many investigators have used the addition to or removal from the diet of eggs as a means of increasing or decreasing cholesterol intake in experiments with human subjects, since eggs provide a concentrated source of cholesterol (about $270 \mathrm{mg} / \mathrm{egg}$ ). Many such experiments, conducted under well controlled conditions in metabolic wards, demonstrated increases of $10-20 \%$ in plasma cholesterol concentration following the consumption of one to two eggs. The baseline or control diet usually contained little or no cholesterol (Glueck \& Connor, 1978). In contrast, experiments in which one or two eggs were added to normal mixed diets, that generally contribute about $400-500 \mathrm{mg}$ cholesterol/d, have shown no significant rises (e.g. Bronsgeest-Schoute et al. 1979a, b; Buzzard et al. 1982; Flynn et al. 1979) or only small (less than 10\%) rises (Roberts et al. 1981). Addition of crystalline cholesterol to diets does not seem to influence plasma cholesterol concentration (Connor et al. 1961).

Why is the evidence so equivocal in man? Several factors have to be considered. First, as alluded to previously, the results gained in a metabolic ward where nutrient intakes can be standardized and measured with precision and where adherence can be maximized, are likely to be more clear-cut than in 'free-living' subjects where information and control must lack precision. Second, the basal or starting concentration of plasma cholesterol is important. Keys et al. (1965) suggested that the individual response to dietary change could be predicted by the initial concentration of plasma cholesterol, persons with hypercholesterolaemia having a greater response to diet. Mistry et al. (1981), however, reported a lack of association between individual response to egg-yolk cholesterol and the initial concentration of plasma cholesterol. Third, it should be mentioned here that supplying additional eggs to diets provides more than simply extra cholesterol. The egg yolk is rich in phospholipids, whose fatty acids are predominantly unsaturated, and there are interactions between dietary cholesterol and fatty acids. A desire to simulate a 'real life situation' so that the experimentation is more relevant to practical diets and to the provision of dietary advice is usually incompatible with the precise experimental design needed to establish concepts or elucidate mechanisms. Nutritionists have to make up their minds which course to follow and to make it clear to their readership what the limitations of interpretation may be.

The fourth problem is that dietary cholesterol may not influence all plasma lipoprotein classes equally. Thus, Appelbaum-Bowden et al. (1984) and Sacks et al. (1984) found that supplementation of the diet with eggs significantly increased plasma LDL but not total cholesterol concentration. This implies a differential change in HDL. Beynen \& Katan (1985), however, observed an increase in HDL as well as LDL on cholesterol feeding. Unusual lipoproteins such as HDLc (Mahley et al. 1978) and $\beta$-VLDL (Nestel et al. 1982) have also been reported to occur as a result of cholesterol feeding. Moreover, there is controversy as to whether the response to dietary cholesterol is positively or negatively associated with the basal concentration of HDL (Beynen et al. 1987). 
Fifth, and most important, it is well known that certain individuals respond strongly and others weakly to dietary cholesterol (hyper- and hyporesponders; Beynen et al. 1987). Thus, inbred strains of rabbits, rats, mice and monkeys, differing in their sensitivity to dietary cholesterol, have been extensively studied (Beynen et al. 1987). As well as differences between inbred strains, there are also substantial differences between individuals within inbred strains or in randomly bred colonies. The evidence for this phenomenon is the more convincing since there is a relatively high correlation between the responses of animals to a dietary challenge and the responses to subsequent challenges. In these animals, differences in responsiveness to dietary cholesterol have a strong genetic basis.

In man, the existence of this phenomenon has been more difficult to prove experimentally because of genetic heterogeneity and an inherently smaller sensitivity: greater than that of rats; much less than that of rabbits or monkeys. Evidence reviewed by Beynen et al. (1987) amply demonstrates its existence. These authors point out that one will always find individuals who appear hyper-responsive in one experiment and hyporesponsive in another. This is because of the phenomenon of within-person variability of plasma cholesterol which is independent of diet and calculated to be responsible for about $25 \%$ of the apparent variance in response between subjects, even if as many as twelve independent blood samples were used to determine each person's blood cholesterol. It is important to realize, therefore, that predictive formulas, such as those of Keys et al. (1957) and Hegsted et al. (1965) hold only for group means and not for individual subjects.

Several mechanisms may be considered in trying to account for these individual responses: differences in absorption of dietary cholesterol; differences in cholesterol biosynthesis; in the output of LDL by the liver or in the receptor-mediated clearance of LDL from the plasma; differences in sterol excretion from the body or differences in the accumulation of cholesterol in body tissues. All these aspects have been reviewed exhaustively and very readably by Beynen et al. (1987) and will be returned to during the discussion of the effects of different dietary fatty acids.

\section{DIETARY SATURATED AND POLYUNSATURATED FATTY ACIDS}

Feeding experiments with experimental animals over four decades have generally led research workers in this field to the conclusion that giving diets in which the fat component comprises predominantly saturated fatty acids leads to concentrations of plasma cholesterol that are significantly higher than those resulting from diets in which PUFA predominate. Among the species studied have been rats (e.g. Hegsted et al. 1957); rabbits (e.g. Moore \& Williams, 1966; Richard et al. 1982); pigs (e.g. Richard et al. 1983) and non-human primates (e.g. Babiak et al. 1985; Johnson et al. 1985). There are, however, some interesting anomalies that are rarely remarked on but should, perhaps, not be entirely forgotten. Wiggers et al. $(1977 a, b)$ found that dietary supplementation with soya-bean oil (from 200 to $500 \mathrm{~g} / \mathrm{kg}$ diet) resulted in higher plasma cholesterol concentrations in rats and calves compared with supplements of tallow.

Similarly, Richard et al. (1980) found the plasma cholesterol concentrations of calves given soya-bean or maize oil to be higher than those of a group given hydrogenated vegetable fat shortening or tallow. Although the basic concept that saturated fatty acids are hypercholesterolaemic and PUFA are hypocholesterolaemic is firmly accepted, the interpretation of many of these experiments and their relevance to man remain problematical for several reasons to be explored later.

Keys et al. (1957) performed painstaking studies on men under carefully controlled conditions in metabolic units, giving them diets with or without fat in amounts up to $35 \%$ of energy, provided by maize, soya-bean, sunflower seed, rapeseed, safflower, cottonseed, 
coconut, olive, pilchard, and menhaden oils, and butterfat. Their general conclusion was that saturated fatty acids were twice as effective in raising plasma cholesterol concentration as PUFA were in depressing it, as summarized by the equation:

\section{$\Delta$ Cholesterol $=2 \cdot 7 \Delta S-1.3 \Delta P$}

This formula, quoted previously, failed when the dietary change involved large amounts of cocoa butter and discrepancies also appeared when they applied the formula to the results of others with beef tallow, cocoa butter or hydrogenated coconut oil (see Ahrens et al. 1957; Connor et al. 1964; Erickson et al. 1964). Keys et al. (1965) concluded that the only saturated fatty acids with cholesterol raising activity were lauric (12:0), myristic (14:0) and palmitic (16:0) acids. Those with chain lengths lower than twelve $\mathrm{C}$ atoms (occurring mainly in milk fat, coconut and palm-kernel oils) are ineffective because of their mode of absorption (see earlier section on lipid metabolism). The reason why stearic acid (present in most oils, but in particularly large quantity in cocoa butter and also in beef fat) is also ineffective remains obscure. Bonanome \& Grundy (1988) recently re-investigated the cholesterolaemic effects of stearic acid (18:0). The stearic acid was present in a synthetic fat and was given in a liquid-formula diet and compared with two other formulas that contained a high proportion of palmitic or oleic acids. The authors concluded that stearic acid was as effective as oleic acid (see p. 74) in lowering plasma cholesterol concentration when either replaced palmitic acid in the diet. Stearic acid was absorbed as efficiently as oleic, so that the differences in cholesterolaemic effect were unlikely to be due to differences in absorption. A possible explanation is the rapid desaturation of stearic to oleic acid, once stearic acid has been assimilated into body tissues.

Much attention has also been devoted to the question of how the degree of unsaturation and the positions of the double bonds in the $\mathrm{C}$ chain of the fatty acids are related to the magnitude of the hypocholesterolaemic effect without, to this day, arriving at a clear-cut conclusion. Monounsaturated fatty acids, those having the lowest degree of unsaturation and complexity, were omitted from predictive equations and will be discussed separately later (p. 72). Many early experiments appeared to suggest a significant correlation between the number of double bonds and the magnitude of the hypocholesterolaemic effect. Later studies, with dietary inclusion of highly unsaturated marine oils, compared with vegetable oils such as maize oil, seemed to confirm this in man (Kingsbury et al. 1961; Kaneda \& Alfin-Slater, 1963; Harris et al. 1983). Others have found minimal influence of marine oils on plasma cholesterol or LDL-cholesterol compared with large effects on plasma triacylglycerols or VLDL-triacylglycerol (e.g. Nestel et al. 1984).

The P:S values in the diets containing the marine oils were, however, lower than those in diets containing maize oil, so that the cholesterolaemic effect is not related in a simple way to the total unsaturation of the diet. (It should also be noted that the cholesterol content of marine oils is relatively high, whereas there is none in maize oil, a point that will be discussed later.)

Problems of interpretation could also be introduced if, superimposed on the effects due to total unsaturation, there is also an influence of double-bond position. Thus, Connor et al. (1981) found that $n$-3 PUFA were, weight-for-weight, more potent than $n$-6 PUFA in reducing plasma cholesterol concentration. Horrobin \& Manku (1983) claimed that the hypocholesterolaemic effect in man of $\gamma$-linolenic acid (n-6), a metabolite of linoleic acid formed by one desaturation, had a hypocholesterolaemic effect compared with linoleic acid that was disproportionate to its degree of unsaturation. The experimental diet contained 3-4 g evening primrose (Oenothera biennis) oil/d which contains much more linoleic $(72 \%)$ than $\gamma$-linolenic $(9 \%)$ acid. The authors predicted a fall in plasma cholesterol of 0.054 $\mathrm{mmol} / \mathrm{l}$ from the amount of linoleic acid present in the diet, using the Keys equation, 
whereas the measured fall was $0.814 \mathrm{mmol} / \mathrm{l}$. They concluded that the additional $0 \cdot 760$ $\mathrm{mmol} / 1$ fall must have been due to the $\gamma$-linolenic acid. The control group was given a placebo, the nature of which was not stated. A more useful control would have been an oil containing the same amount of linoleic acid with no $\gamma$-linolenic acid. The matter is unlikely to be resolved by using oils that contain such complex mixtures of fatty acids. In a recent human study, Boberg et al. (1986) found that $\gamma$-linolenic acid had no effect on plasma triacylglycerol concentrations in patients with an abnormally high concentration of these lipids, while $n-3$ fatty acids caused a significant reduction in the triacylglycerol content of all lipoprotein fractions.

One point on which there seems to be universal agreement is that the cholesterolcontaining lipoprotein fraction that is influenced most by the cholesterolaemic effects of either saturated or polyunsaturated fatty acids is LDL, certainly in man (e.g. Becker et al. 1983; for review, see Goldberg \& Schonfeld, 1985). The general reader should be aware that while LDL is the main cholesterol-carrying lipoprotein in man, this is by no means so in all species. Thus guinea-pigs, pigs, and a few non-human primates resemble man in this respect, while in rats, rabbits, domestic cattle, most carnivores and many non-human primates HDL are the predominant lipoproteins carrying cholesterol. This can sometimes make comparisons between species difficult or even impossible and may be at the root of some of the anomalous findings described earlier.

The extent to which lipoproteins other than LDL are affected by dietary fatty acids seems to depend on a number of interacting factors that may include the initial concentration of the lipoproteins (i.e. whether the subject has a plasma lipoprotein pattern that is 'normal' or has elevated concentrations of one or more of the major lipoprotein classes) and the quantity and nature of the dietary fat (i.e. types of unsaturated fatty acids present, concentration of dietary cholesterol, etc). Thus, the principal effect of fish oils containing a high proportion of $n-3$ fatty acids is to reduce the concentrations of plasma cholesterol and triacylglycerols, mainly in the VLDL fraction, compared with vegetable oils with a high proportion of $n-6$ fatty acids that primarily lower LDL concentrations (Goodnight et al. 1982; Harris et al. 1983). As few as $2 \mathrm{~g} n-3$ PUFA/d are sufficient to reduce plasma VLDL in patients with elevated concentrations of this lipoprotein class (Simons et al. 1985), whereas very high intakes $(24 \mathrm{~g} / \mathrm{d})$ also reduce the concentrations of LDL and apoB (Illingworth et al. 1984). Nestel et al. (1984) found that a diet containing $30 \%$ of energy as fish oil lowered VLDL lipids and the concentration of apoB compared with safflower oil in men with normal plasma lipids or with hypertriacylglycerolaemia and Baudet et al. (1984) also concluded that the plasma lipoproteins of normal and hypercholesterolaemic subjects responded in a similar manner to different dietary fatty acids. It is well documented that patients with non-insulin-dependent diabetes (NIDDM) are prone to elevated VLDL. These conditions are also strongly associated with upper body obesity (Stern \& Haffner, 1986). According to Schectman et al. (1988), supplementation of the diets of twelve NIDDM patients with fish oil significantly reduced plasma triacylglycerols and VLDL-triacylglycerol concentrations but caused a mild elevation of LDL-cholesterol and apoB concentrations.

When the $\mathrm{P}: \mathrm{S}$ is very high, dietary PUFA seem to reduce the concentration of HDL in man. Kwiterovitch et al. (1985) observed a fall in the concentration of HDL-cholesterol in children with hyperlipoproteinaemia given diets with a P:S of 2 and in healthy adults given diets with a P:S of $2 \cdot 0$ (Jackson et al. 1984) or 3.2 (Kohlmeier et al. 1985) HDL-cholesterol concentrations were also reduced. In contrast, Sacks et al. (1985) found no relationship between the concentration of HDL-cholesterol and any nutrient in the diet of vegetarians when the P:S was not higher than 1.0. Weisweiler et al. (1985) also failed to observe changes in HDL-cholesterol concentration when VLDL and LDL concentrations were reduced 
employing diets with a P:S of 1.0. Janetschek et al. (1983) demonstrated that increasing the $P: S$ of a diet from 0.3 to 1.0 without altering the total fat content (30\% of energy) effectively lowered total plasma and LDL-cholesterol concentrations in normal females without affecting the concentration of HDL. In the experiments of Blaton et al. (1984), HDL-cholesterol was actually increased in normal and hypercholesterolaemic subjects given a diet with a P:S of 1.59. Stein et al. (1975) observed greater plasma cholesterol lowering by diets enriched with polyunsaturated fatty acids in those subjects whose initial plasma cholesterol concentrations were highest.

Just as there are wide differences in individual responses to dietary cholesterol, so there are hypo- and hyper-responders to dietary fatty acids (Beynen et al. 1987). Indeed, Beynen et al. (1986) have demonstrated that the plasma cholesterol responses of rabbits given a cholesterol-free diet in which maize oil replaced coconut oil closely paralleled their responses to dietary cholesterol. Since the early experiments of Ahrens et al. (1957), it has been clear that there were wide differences in responses to different fatty acids in man, and this is confirmed by re-analysing the findings from the classical studies of Keys and his colleagues in Minnesota (Jacobs et al. 1983) and from studies performed by the Unilever group (see Beynen et al. 1987). It is apparent that one can find subjects with a consistently high or low response but that total insensitivity is rare. When Beynen et al. (1987) changed the P:S of experimental diets from 1.91 to 0.22 at a constant intake of cholesterol (500 $\mathrm{mg} / \mathrm{d})$, the response of plasma cholesterol was positively correlated $(r 0.50, n 23, P<0.05)$ with their responses to dietary cholesterol. These authors also stress that a major part of the apparent variance between persons is due to random within-subject fluctuations of plasma cholesterol that are unrelated to diet, a point made strongly by Ancel Keys in a recent analysis of findings from Israel (Keys, 1988).

There have been few studies on the long-term effects of dietary PUFA. Hostmark et al. (1980) reported that, although plasma total cholesterol increased with age in two groups of rats fed on a diet containing either coconut or sunflower oil $(100 \mathrm{~g} / \mathrm{kg}$ diet $)$, there were no significant differences in plasma cholesterol concentrations due to the two dietary fats. In contrast, Kritchevsky et al. (1982) reported that the plasma lipids of rabbits fed on a maizeoil-supplemented diet remained unaffected after 9 months compared to a group consuming a diet supplemented with fats containing predominantly saturated fatty acids. The contradiction between these two experiments may be due to the sources of polyunsaturated fat used rather than to species differences.

In man, most studies on plasma lipids in different age groups have been cross-sectional and one cannot necessarily infer longitudinal changes. Such longitudinal studies as there are suggest increases in plasma cholesterol with age, especially in men, but it is not easy to separate these from changes in body fat mass (e.g. Kritchevsky, 1980; Wallace \& Anderson, 1987).

\section{MONOUNSATURATED FATTY ACIDS}

Since Keys et al. (1965) developed their equation to predict the effects of changes in dietary fatty acids on plasma cholesterol, the cholesterolaemic effect of monounsaturated fatty acids has been largely ignored since they did not appear as a term in the equation, having been regarded as 'neutral' in respect of cholesterolaemia. Recently, this assumption has been re-evaluated.

Mattson \& Grundy (1985) compared the effects of liquid formula diets comprising either predominantly saturated ('high saturates'), monounsaturated ('high monounsaturates') or polyunsaturated ('high polyunsaturates') fatty acids on plasma lipids and lipoproteins. The diet containing predominantly oleic acid was as effective in lowering LDL-cholesterol as linoleic acid in subjects with normal plasma triacylglycerol concentrations, but with a suggestion that oleic acid did not reduce the concentration of HDL as did linoleic acid. 
Neither type of unsaturated fatty acid had a strong effect on lipoproteins in patients with hypertriacylglycerolaemia. A problem in comparing the two variants of safflower oil, one rich in oleic, the other in linoleic acid, is that the 'monounsaturated' oil contained $17.4 \%$ linoleic acid, which may have been all that was required to exert a cholesterol-lowering effect.

Grundy (1986) compared isoenergetic liquid formula diets rich in either monounsaturated fatty acids or carbohydrates for their cholesterol-lowering activity. Compared with a diet rich in saturated fatty acids, both the high-monounsaturates diet and the lowfat diet lowered plasma cholesterol by $13 \%$ and $18 \%$ respectively. Compared with a diet rich in saturated fatty acids, the low-fat diet raised plasma triacylglycerols, whereas the monounsaturates diet had no effect. The LDL: HDL ratio was significantly lower after the monounsaturates diet than after the low-fat diet.

Mensink \& Katan (1987) studied the effect of diets containing predominantly monounsaturated fatty acids or complex carbohydrates on HDL-cholesterol in healthy men and women. Plasma total cholesterol concentrations were lowered by about $8 \%$ with both diets, but HDL-cholesterol fell by $13 \%$ with the carbohydrate diet and rose slightly $(2 \%)$ with the monounsaturated fatty acid diet. It was concluded that the latter 'caused a specific fall in non-HDL cholesterol'. Plasma triacylglycerol concentrations rose with the high-carbohydrate diet. The authors showed that Grundy's (1986) findings could be extended to natural solid mixed diets.

Baggio et al. (1988), in a well designed and controlled trial, compared the influence on plasma lipoproteins of a low-fat diet and a high-fat diet in which olive oil was the major component and demonstrated significant effects that could be specifically related to oleic acid, using sensible practical diets. Energy, protein and cholesterol intakes of the subjects were the same after 6 weeks on the trial. In the first 3 weeks, the subjects received the lowfat diet and in the second, the high-fat diet. The P:S was the same in each diet and was relatively low (0.36). Average reduction of total plasma cholesterol was the same ( $-9.5 \%)$ with both diets; HDL-cholesterol did not change and triacylglycerol concentrations were significantly reduced on the high-fat diet.

Grundy et al. (1988) studied ten elderly men aged 61-70 years on three diets in sequence, 6 weeks/diet. The first two diets supplied $40 \%$ of energy as fat, while the third diet provided only $20 \%$ energy as fat. The fat in diet 2 , the 'monounsaturates diet' was provided mainly by high-oleic safflower oil. Compared with the 'high-saturates diet' (diet 1), the high-monounsaturates and low-fat diets resulted in the same reductions in total plasma cholesterol $(-13.5 \%)$ and LDL-cholesterol $(-19 \%)$. There were no differences in triacylglycerol concentrations on any diet, while the low-fat diet resulted in a significant reduction in HDL-cholesterol compared with the high-fat diets.

The results of these five studies are summarized in Table 1. All involved rather small numbers of subjects and most suffered from lack of information on previous diet. More seriously, in the study of Grundy et al. (1988), there were enormous differences between diet 1 and diets 2 and 3 in both cholesterol content $(900 v .200 \mathrm{mg} / \mathrm{d})$ and in $P: S(0.3 v .0 .86)$. The cholesterol-lowering effects of the high-monounsaturates and low-fat diets could simply have been due to the differences in cholesterol intake, but because of large differences in the $\mathrm{P}: \mathrm{S}$ it is impossible to draw a firm conclusion about the specific effects of monounsaturated fatty acids.

In summary, despite the defects of individual studies, a general conclusion is that dietary lipids containing a high proportion of monounsaturated fatty acids maintain relatively low plasma total cholesterol and LDL-cholesterol concentration even when present in the diet as a relatively high proportion of energy. They do not reduce plasma HDL-concentrations, nor do they elevate plasma VLDL and total triacylglycerol concentrations. 


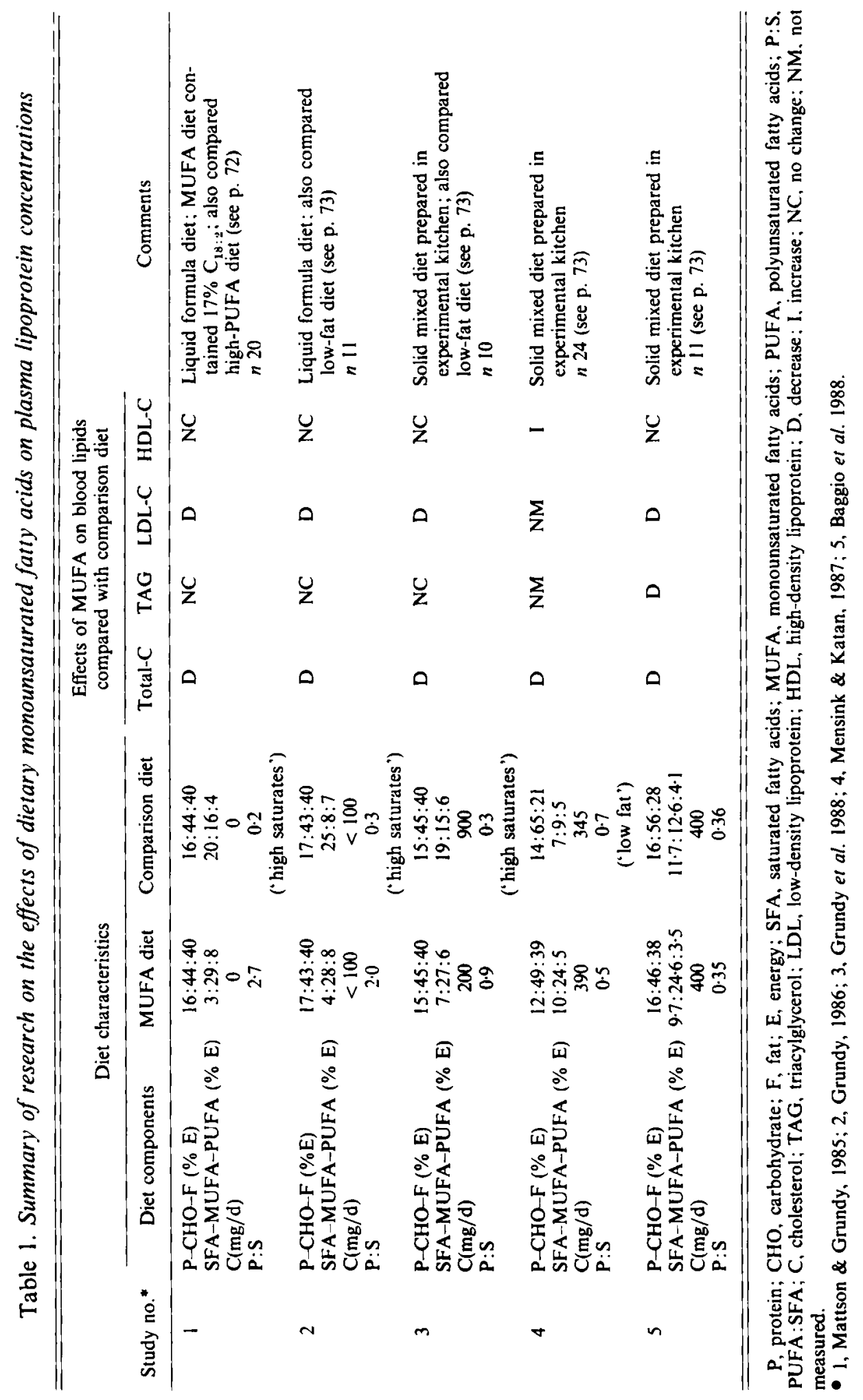




\section{INFLUENCE OF TRIACYLGLYCEROL STRUCTURE}

Natural triacylglycerols are characterized by a stereospecific distribution of fatty acids on the three positions of the glycerol backbone rather than a random distribution. There have been several suggestions in the literature that, irrespective of fatty acid composition, the distribution of fatty acids in the triacylglycerol molecules affects cholesterolaemia. Thus, there have been suggestions that linoleic acid is more hypocholesterolaemic (e.g. Tamamoto et al. 1971) and stearic acid more hypercholesterolaemic (McGandy et al. 1970) when present at the $\mathbf{s} n-2$-position than when esterified in positions $s n-1$ or $s n-3$. The fact that stearic acid is normally esterified at position 1 , rarely at position 2 , may explain the apparent 'neutral' effect of stearic acid on blood cholesterol (see previous discussion).

A Belgian research group demonstrated that butter was much less hypercholesterolaemic if the triacylglycerol fatty acids were randomized by the technique of interesterification (Christophe et al. 1978). Kritchevsky et al. (1973) showed that the atherogenic effects of peanut oil for rats could be abolished if the peanut oil fatty acids were randomized. In a later paper, the structural features of the different lipids were examined in more detail (Myher et al. 1977). Therefore, much more attention than hitherto needs to be given to the structure of lipids rather than their fatty acid compositions, and it is probable that many of the apparent anomalies recorded in the literature may be resolved on this basis.

\section{EXPERIMENTAL DESIGN AND PROBLEMS OF INTERPRETATION}

We have seen that there is a general trend for blood lipid concentrations to be raised when the diet contains a preponderance of saturated fatty acids and for them to be lower when unsaturated fatty acids predominate but that striking anomalies are not uncommon. Factors unrelated to diet, such as temporal variations in blood lipids within individuals and hyper- and hyporesponsiveness to nutrients, clearly contribute to variability. Poor experimental design and failure to discuss the implications of factors that are difficult to control compound the problem. Among the latter is the simple fact that, for all practical purposes, all natural glycerides contain mixtures of saturated, monounsaturated and polyunsaturated fatty acids within the same molecules. Moreover, within these broad fatty acid classes there is heterogeneity with respect to chain length and double-bond structure, all factors that may influence lipoprotein metabolism as indicated previously. Thus, because of this heterogeneity, the term 'saturated fats' is meaningless and one can only speak of 'saturated fatty acids'. These terms contribute further to the state of confusion. This is not irrelevant to the problem of interpretation, since many publications have reported cholesterolaemic effects of 'polyunsaturated', 'monounsaturated ' or 'saturated ' fats, when the presence of significant amounts of other fatty acids in the diets or oils employed could have been responsible for some of the effects observed.

The use of natural oils raises other problems due to the presence of minor lipid fractions that are different in each oil and could influence lipoprotein metabolism in ways that are, at present, ill-defined. Thus, maize oil, which has been used as the archetypal 'polyunsaturated fat', contains a particularly large proportion of tocopherols, especially $\gamma$ tocopherols, and these may need to be taken into account. Some oils, including maize and palm, and the lipids from some cereal grains contain tocotrienols that, in very low dietary concentrations, may lower plasma cholesterol by a mechanism that depends on their specific inhibition of HMG-CoA reductase (Burger et al. 1982).

Much more serious is the failure of a surprisingly large number of studies, involving both man and experimental animals, to balance the cholesterol content of the diet. In nutrition, as in other experimental sciences, the aim should be to design treatments such that as many 
variables as possible are controlled, allowing the experimenter to draw conclusions based on changes in one variable. (In dietetics, where one is concerned with the effects of practical diets on human health and well-being, such scrupulousness is out of place and the two should not be confused.) In all the experiments described in the foregoing two sections, where authors have compared the cholesterolaemic effects of diets based on vegetable oils as the source of the fatty acids under investigation, the diet will have contained no cholesterol unless it was present in other components of the experimental diet or it had been deliberately added. Likewise, when animal fats and oils (including the highly polyunsaturated fish oils) have been employed, the diet will have contained variable amounts of cholesterol depending on the fat used. Unless the experimenter has taken steps to equalize the cholesterol content, the effects reported will be the result of complex interactions between the cholesterol, fatty acids and possibly other nutrients, although the material is more often than not presented to the reader as reflecting exclusively differences in the fatty acid composition. Indeed, Mulvihill \& Walker (1984) showed that in mice the plasma cholesterol concentration could be lowered effectively by increasing the $P: S$ of the dietary fat (up to 5.0) in the presence of dietary cholesterol, but that changing the $P: S$ was quite ineffective when no dietary cholesterol was present. As little as $1 \mathrm{~g}$ cholesterol $/ \mathrm{kg}$ diet was required for an effect to be observed.

Another interpretational problem is caused by the use of different levels of dietary fat. The very carefully executed and comprehensive study of Hegsted et al. (1965) concluded that changes in human plasma cholesterol concentration were more closely related to the proportions of fatty acids in the dietary fat than to the contribution of fat as a percentage of total energy. Only two levels of dietary fat were employed by these authors, namely 22 and $38 \%$ of energy. Few if any studies, whether examining the effects of dietary cholesterol or of different fatty acids, have ascertained whether there is a dose-response relationship between the experimental variable(s) and the biological effect measured, and unless this is done the conclusions that can be drawn must remain tentative.

In several more recent human experiments it appears that low-fat diets have had effects on plasma lipids similar to those of higher-fat diets containing high inclusions of polyunsaturated (Brussaard et al. 1980; Sacks et al. 1986) or monounsaturated fatty acids (Grundy et al. 1988). Sacks et al. (1986) showed decreased concentrations of LDL- and HDL-cholesterol on a diet containing $22 \%$ of energy as fat in subjects with normal plasma lipids. The reduction in LDL- and HDL-cholesterol, however, cannot be confidently attributed to lower levels of fat in the diet because this diet contained considerably less dietary cholesterol as well as less fat. The measurements reported were of HDL- and LDLcholesterol concentrations only, with no indication of changes in the concentrations of the lipoproteins themselves. Williams et al. (1986) correlated the concentrations of various plasma lipids from seventy-seven men on unrestricted diets with their dietary fat intakes. They found that PUFA consumption was negatively correlated with concentrations of triacylglycerols, total plasma cholesterol and LDL- and VLDL-cholesterol.

The experiments reviewed here illustrate an important difference between most animal and human studies. Most experiments in man were conducted in 'developed' countries where the initial plasma cholesterol concentrations of the subjects are usually relatively high. Substitution of the fat in these diets with vegetable oils that contained no cholesterol and increased the $P: S$ ratio could clearly result in impressive reductions of plasma cholesterol concentration. In contrast, laboratory animals such as rats and rabbits would normally have had initially low plasma cholesterol concentrations. Increasing the concentration of fat in the diet under these conditions (e.g. Hegsted et al. 1957; Avigan \& Steinberg, 1958) caused elevated plasma cholesterol concentrations whatever the composition of the fat, although the effect was greater when the fatty acid composition was 
predominantly saturated than when it was mainly polyunsaturated. Another difficulty in making animal and human comparisons relates to the amount of cholesterol fed to the experimental animals in many experiments. For example, to produce hypercholesterolaemia in rats, Bochenek \& Rodgers (1978) added $10 \mathrm{~g}$ cholesterol/kg diet. Adjusting for bodyweight and food intake, this amounts to about fifty times the average British intake of cholesterol $(400 \mathrm{mg} / \mathrm{d})$. This is typical of many animal studies. Although diets rich in PUFA compared with saturated fatty acids seem to result in lower plasma cholesterol concentrations over a wide range of dietary cholesterol levels, the effects observed in the presence of such high levels of dietary cholesterol may mask the underlying mechanisms involved and undoubtedly make comparisons between animal and human studies more difficult.

Even in those experiments in which Western subjects were given a low-fat diet as a comparison (e.g. Hegsted et al. 1965), the period for which they received this regimen was relatively short compared with the time since childhood when they had been consuming a relatively rich diet. Studies with experimental animals have given equivocal answers to the question of whether early dietary experience conditions plasma lipid responses to diet (e.g. Beynen et al. 1987). Experiments in man are rare but the same authors showed that responsiveness to dietary cholesterol was significantly and negatively correlated with habitual cholesterol consumption, a relationship that persisted after linear regression analysis. Others, however, have found no such relationship (Mistry et al. 1981).

Our conclusion is that the findings are consistent with the view that the major dietary lipid affectors of plasma lipid concentration are the fatty acids lauric, myristic and palmitic acids. The contribution of unsaturated fatty acids is mainly to prevent the rise in plasma lipid concentrations induced by these fatty acids. What is the mechanism by which this occurs? Surprisingly, this question has yet to be resolved and a detailed appraisal of possible mechanisms is beyond the scope of this review. Beynen et al. (1987) have effectively reviewed some hypotheses, although they were mainly addressing the question of hypo- and hyper-responders to dietary cholesterol. Since there is a strong parallelism between response to cholesterol and to saturated fatty acids, the mechanism(s) may be shared at least in part. Paul et al. (1980) have reviewed specifically the mechanism of the hypocholesterolaemic effect of PUFA without reaching a definitive conclusion.

Briefly, saturated fatty acids may operate in one or more of the following ways. (1) By suppressing the excretion of bile acids that occurs at each passage of the enterohepatic circulation. There is some evidence for (see Oh \& Monaco, 1985) and against (see Shepherd et al. 1980) this idea in man. According to McNamara (1987), the excretion of steroids in response to an increase in $\mathrm{P}: \mathrm{S}$ is transient. Small differences between the losses of bile acids induced by saturated or unsaturated fatty acids at each enterohepatic cycle may not be detectable over a short period, but over extended periods may be sufficient to be reflected in changes in plasma cholesterol concentrations. (2) By enhancing the production of cholesterol and of LDL in the liver, possibly by reducing the degree of control exerted on the enzyme HMG-CoA reductase (Mistry et al. 1981; Beynen et al. 1987) or by effects on apoB biosynthesis (Illingworth et al. 1984). (3) By retarding the catabolism of lipoproteins either through influencing degradative enzymes such as lipoprotein lipase (Jackson et al. 1978), changes in LCAT activity (Janetschek et al. 1983) or changes in the receptor-mediated uptake of LDL by the specific receptor (e.g. Shepherd et al. 1980; Gavigan \& Knight, 1981; Baudet et al. 1984; for review, see Goldberg \& Schonfeld, 1985). Beynen \& Katan (1985) have hypothesized that, since cholesterol synthesis is subject to feedback inhibition by cholesterol derived from LDL, and that in subjects with the most pronounced increases in plasma cholesterol concentrations the reduction in cholesterol synthesis is negligible, the mechanism of down-regulation of 
cholesterol synthesis may be ineffective in hyper-responders. As hypo- and hyperresponsiveness to dietary cholesterol and to dietary saturated fatty acids has also been shown to coincide in man (Katan \& Beynen, 1986) these authors concluded that a common pathway may exist for the hypercholesterolaemic effects of dietary saturated fatty acids and dietary cholesterol, possibly involving the suppression of LDL-receptor activity. (4) By affecting the distribution of cholesterol in the body so that relatively more is carried in the plasma and less resides in body tissues; there is little evidence for this in man. (5) By inducing changes in the structure of membranes and the lipoproteins themselves. It is known that compositional changes may be induced by changes in dietary fat composition in both membranes (McMurchie, 1988) and lipoproteins (Mahley, 1978; Pownall et al. 1980; Goldberg \& Schonfeld, 1985) and that these are associated with changes in membrane fluidity (McMurchie, 1988) and lipoprotein structure (Mahley, 1978; Pownall et al. 1980). The implications of such changes for cholesterolaemia have been considered but no comprehensive hypothesis has been proposed or tested.

\section{PRACTICAL AS DISTINCT FROM EXPERIMENTAL DIETS}

\section{Habitual diet and blood lipoprotein concentrations}

The foregoing discussion has reviewed experimental evidence relating dietary lipids with plasma lipid concentrations. In terms of practical nutrition, a relevant question is: how are people's plasma lipids influenced by their normal habitual diets and to what extent is diet important within the context of other lifestyle factors and genetic background?

An important limitation in assessing the importance of habitual diet in determining plasma lipids is our limited knowledge of the contribution of inheritance and the extent to which genetic and environmental factors (of which diet is but one; see Blackburn, 1987) interact. This is an area of rapidly expanding knowledge, however. Monogenic defects leading to extreme hyperlipoproteinaemias are now well characterized but affect only a small proportion of the population. For example, the frequency of the heterozygous form of familial hypercholesterolaemia is one in 500 and of the homozygous form, one in 1000000 of the general population (Galton, 1985; Brown \& Ginsberg, 1987). These singlegene defects may be associated with, for example, defective synthesis of the LDL receptor and failure to regulate cholesterol biosynthesis via control of HMG-CoA reductase (Goldstein \& Brown, 1984). Recently, there has been considerable interest in a condition in which there is an elevation of a unique lipoprotein designated $\mathrm{Lp}(\mathrm{a})$. This lipoprotein is similar in structure to LDL but with higher density and different electrophoretic mobility (Grinstead \& Ellefson, 1988). Its function is unknown but plasma concentrations exceeding $300 \mathrm{mg} / \mathrm{l}$ are associated with a 2- to 3-fold risk of cardiovascular disease. Its plasma concentration is independent of diet and determined largely by heredity (Albers et al. 1977).

Most inherited hyperlipidaemia is due to polygenic inheritance, but the pattern of inheritance is not clear from family screening (Brown \& Ginsberg, 1987). Techniques for studying genetic polymorphisms hold out the prospect of analysing the human genetic diversity associated with different plasma lipoprotein patterns (Galton, 1985).

Population studies, both prospective and retrospective, have generally demonstrated a correlation between low-fat low-cholesterol diets and relatively low concentrations of plasma lipoproteins and indeed, have frequently been used to support recommendations for lipid-lowering in 'Western' countries (e.g. see Keys, 1970; Blackburn, 1987). These studies have usually been cross-sectional in design and their usefulness is limited in this respect. Thus, comparisons have been made between Japanese living in urban and rural areas (Ueshima et al. 1982) or Polynesians consuming different levels of dietary saturated fatty acids (Prior $e t$ al. 1981). In the USA, the correlation coefficient between P:S and 
plasma lipid concentration was small (Shekelle et al. 1981) and the Tecumseh study could not demonstrate a significant relationship between fat, cholesterol or other macronutrients in the diet and plasma lipids (Nichols et al. 1976). There are a number of reasons why this might be so. Within an affluent population, dietary differences tend to be small and dietary fatty acid and cholesterol intakes of individuals correlate poorly with blood lipids. It is also difficult to assess the part played by other factors such as total energy intake, other dietary constituents such as complex polysaccharides, type of protein and absorbic acid, physical activity, alcohol consumption and stress (Gordon et al. 1984). There is also the problem that, with few exceptions, measurement of fat intake has been poor and the information gained is generally unreliable (see earlier section on dietary lipid consumption, p. 65).

More recent evidence that little relationship exists between the type of dietary fat habitually consumed and plasma lipids comes from the study of Berry et al. (1986). They used adipose tissue fatty acid composition as an indicator of habitual diet and concluded that the adipose tissue composition and, by implication, the type of dietary fat eaten explains only a small percentage (1-19) of the variance in plasma lipids in subjects with plasma lipid concentrations in the normal range. The size of the population studied was 413 and the very wide variations in $P: S$ quoted indicate that there were wide differences in the composition of fat consumed (although this method is unable to provide information on the amount of fat consumed). The method was chosen because it provides a much more reliable measure of the composition of fat intake over a long period of time than short- or long-term recall studies or even $7 \mathrm{~d}$ weighed inventories. It serves to remind us that possibly the greatest weakness in most or all the studies contributing to current dietary recommendations is the quality of the dietary information available.

The 'Caerphilly study' (Fehily et al. 1988) provides evidence for a positive association between saturated fatty acid intake and LDL-cholesterol in 653 45- to 59-year-old men. This evidence is reliable, being based on a weighed inventory method of diet assessment, with a short interval between the diet survey and the cholesterol measurement. Nevertheless, diet as a whole accounted for only 1-7\% of the variance in plasma lipoprotein concentrations and only $1.9 \%$ of the variance in plasma total cholesterol.

Thus, not all studies demonstrate an association between habitual fat intake and plasma lipids and even in studies where such an association existed, the proportion of the variance accountable to diet was extremely small.

\section{Influence of modifying dietary fat on blood lipoprotein concentrations}

In preceding sections, ample evidence has been quoted to confirm that plasma lipoprotein concentrations can be raised or lowered by dietary fat modification under experimental conditions. What is the evidence that such changes can be achieved in everyday life? In fact, it has been consistently difficult to demonstrate that fat-reduced or fat-modified diets reduce plasma cholesterol concentrations in people with plasma cholesterol in the normal range and living under 'normal' conditions.

For example, a study conducted in Helsinki (Frick et al. 1987) examined the changes in two groups, one treated with a drug, gemfibrozil, the other with a placebo. Both groups, however, were given intensive dietary advice similar to that recommended by the Committee on Medical Aspects of Food Policy (COMA) (Department of Health and Social Security 1984) report. The study lasted 5 years and at the start of the trial the average plasma cholesterol was $7.5 \mathrm{~mm}$ compared with $6.3 \mathrm{~mm}$ for the population as a whole. Plasma cholesterol concentrations in the group treated with the drug and diet decreased by $8 \%$ but the total plasma cholesterol of the group given dietary advice alone actually rose $3 \%$.

A recent study in London set out to compare subjects on a typical UK diet with a 
practical fat-modified diet achieved by trimming the fat from meat. In this study, Watts et al. (1988) demonstrated an $8.6 \%$ reduction in plasma cholesterol concentration when subjects were given a diet containing $35 \%$ energy as fat, $14 \%$ energy as saturated fatty acids and a $P: S$ of 0.5 (resembling the recommendations of the COMA Panel (Department of Health and Social Security, 1984)) compared with a diet contributing $42 \%$ energy as fat, $21 \%$ energy as saturated fatty acids and a P:S of 0.27 (similar to an 'average UK diet'). A reduction of $18.5 \%$ was obtained with a more extreme diet contributing $27 \%$ energy as fat, $8 \%$ energy as saturated fatty acids and a $P: S$ of 1.0 . The overall fat reduction was assisted by providing meat from which the fat had been closely trimmed. Regarding the relevance of this study to practical measures for the general population, the limitations were that there were only fifteen subjects whose mean plasma cholesterol concentration was very high $(8.1 \mathrm{~mm})$ and they were studied for only 4 weeks under fairly strict supervision.

An example of a study, much quoted for the ease with which plasma cholesterol could be lowered by giving relatively simple dietary advice to 'free-living' subjects, is the Oslo Study (Hjermann et al. 1981). It cannot be concluded, however, that the results of this study are at all relevant to practical measures for the general population for the following reasons. The subjects (1232 healthy 40- to 49-year-old men) were selected on the basis that their plasma cholesterol concentrations fell in the range $7.5-9.8 \mathrm{~mm}$ : very high by any standards. Before final selection, subjects were given a dietary questionnaire, as a result of which a 'food score' was allocated. Diets with a high food score $(>30)$ were those which by conventional wisdom would be expected to result in low plasma lipoprotein concentrations. All men already on diets with a score $>30$, yet whose plasma lipids fell in the range of concentrations for admission to the study $(7.5-9.8 \mathrm{~mm})$ were excluded from the study. It can be concluded that a previous 'lipid-lowering' diet had had no effect on the total plasma cholesterol of these men and that their high total plasma cholesterol concentrations were due to factors other than diet. Therefore, the study group consisted of men selected as being more likely than others to respond to diet. It is, therefore, improbable that a normal unselected population could achieve this degree of lipid lowering under normal living conditions and the study should not be cited as evidence for this.

The overall conclusion must be that reductions in plasma cholesterol concentrations generally desired by those seeking to reduce CVD mortality can be achieved under supervised conditions in those already having a plasma cholesterol concentration significantly above the mean for the UK population. Achieving these goals in people with average or just above average plasma cholesterol under 'free-living' conditions for sustained periods will be extremely difficult, if not unlikely.

\section{CONCLUSION}

Comparisons of different populations generally show that low average consumption of total fat and saturated fatty acids tends to be associated with low average plasma lipoprotein concentrations, especially the LDL fraction. The observation that plasma lipids in migrants tend to be similar to those in the population of their adopted country has been advanced as evidence for a predominant influence of diet. Confidence in this assumption must be limited, however, because other lifestyle characteristics (stress, exercise patterns, etc.) also change. Moreover, most studies have been cross-sectional rather than longitudinal.

In contrast, studies of individuals within populations have shown no convincing correlation between habitual dietary intake of fat or any other nutrient. McGill et al. (1981) argued that the reasons for this discrepancy may be found in the difficulties in obtaining accurate estimates of the degree of association between the two variables. They might also 
have added the inaccuracies and uncertainties in measuring the variables themselves (i.e. dietary fat intake and individual blood cholesterol values) as discussed in the present review and elsewhere. McGill et al. (1981) concluded, using a rigorous statistical evaluation, that the group correlation may appear larger than individual correlations because (1) averaging reduces the effects of within-subpopulation variation, (2) the group correlation coefficient may be overestimated due to purposive selection, (3) within-subject variability causes the individual correlation coefficient to be underestimated.

At a biochemical level, the evidence is that, under the experimental conditions employed to date, the fatty acids lauric, myristic and palmitic invoke rises in plasma cholesterol, especially in the LDL fraction, while monounsaturated and polyunsaturated fatty acids tend to prevent this rise, but to different degrees depending on their structure. High-fat diets in which unsaturated fatty acids predominate are as effective at maintaining relatively low concentrations of plasma cholesterol as low-fat high-carbohydrate diets, although the latter tend, on average, to elevate triacylglycerols as VLDL and, in some individuals, reduce HDL.

The experimental evidence for these statements, obtained with laboratory animals and human subjects in metabolic units, has to be interpreted with caution because in virtually all studies the experimental fats were natural food fats containing mixed-acid glycerides rather than glycerides containing only a single test fatty acid. Moreover, in most cases, experiments have been poorly controlled to the extent that the fats that were compared differed not only in their fatty acid compositions but also in many minor components, known to influence plasma lipids, and in cholesterol content.

Recommendations made to the general public for modification of diet to reduce plasma LDL are issued in the context of a population where there is little correlation between diet and plasma lipids. Therefore, little change can be expected by this approach. This is not to deny that many individuals with raised plasma lipids may not benefit from well-supervised dietary fat modification. The clinical evidence is very clear on this point.

At a fundamental level, further research is warranted on the dose-related effects of specific fatty acids and especially on the influence of triacyglycerol structure. The influence of diet on HDL, once thought to be minimal but now recognized to be important, deserves more thorough investigation. Another important question on which there is paucity of information is the extent to which individuals adapt to a certain diet or lifestyle. Current evidence is limited to experimental animals and McGill et al. (1981) cite examples of adaptation of plasma cholesterol, rising in early life and falling again later, in baboons (Papio) given diets rich in cholesterol and saturated fatty acids. Finally, in view of the strong relationship between upper body obesity, NIDDM and tissue insulin resistance, the influence of dietary fat on the insulin sensitivity of tissues is also a priority. The results of such research may allow the targetting of specific advice to people who will most benefit rather than the present indiscriminate and ill-defined guidelines to a population that, en masse, is unlikely to benefit.

\section{REFERENCES}

Ahrens, E. H., Insull, W., Blomstrand, R., Hirsch, J., Tsaltas, T. T. \& Peterson, M. L. (1957). The influence of dietary fats on serum-lipid levels in man. Lancet $\mathbf{i}, 943-953$.

Albers, J. J., Adolphsen, J. L. \& Hazzard, W. R. (1977). Radjoimmunoassay of human plasma Lp(a) lipoprotein. Journal of Lipid Research 18, 331-338.

Albers, J. J. \& Segrest, J. P. (Editors) (1986). The Plasma Lipoproteins. Vol. A. Preparation, Strucrure and Molecular Biology; vol. B. Characterization, Cell Biology \& Metabolism. Methods in Enzymology $128,129$.

Appelbaum-Bowden, D., Haffner, S. M., Hartsook, E., Luk, K. H., Albers, J. J. \& Hazzard, W. R. (1984). Downregulation of the low-density lipoprotein receptor by dietary cholesterol. American Journal of Clinical Nutrition $39,360-367$. 
Avigan, J. \& Steinberg, D. (1958). Effects of saturated and unsaturated fat on cholesterol metabolism in the rat. Proceedings of the Society for Experimental Biology and Medicine 97, 814-816.

Babiak, J., Nichols, A. V., Gong, E. L., McMahan, C. A., Kuehl, T. J., Mott, G. E. \& McGill, H. C. (1985). Effects of dietary polyunsaturated and saturated fats on lipoproteins in the baboon. Atherosclerosis 57, 1-17.

Baggio, G., Pagnam, A., Muraca, M., Martini, S., Opportuno, A., Bonanome, A., Ambrosio, G. B., Ferrari, S., Guarini, P., Piccolo, D., Manzato, E., Corrocher, R. \& Crepaldi, G. (1988). Olive-oil-enriched diet: effect on serum lipoprotein levels and biliary cholesterol saturation. American Journal of Clinical Nutrition 47, $960-964$.

Baudet, M. F., Dachet, C., Lasserre, M., Esteva, O. \& Jacotot, B. (1984). Modification in the composition and metabolic properties of human low density and high density lipoproteins by different dietary fats. Journal of Lipid Research 25, 456-468.

Becker, N., Illingworth, D. R., Alaupovic, P., Connor, W. E. \& Sundberg, E. E. (1983). Effects of saturated, monounsaturated, and $\omega-6$ polyunsaturated fatty acids on plasma lipids. lipoproteins, and apoproteins in humans. American Journal of Clinical Nutrition 37, 355-360.

Berry, E. M., Hirsch, J., Most, J., McNamara, D. J. \& Thornton, J. (1986). The relationship of dietary fat to plasma lipid levels as studied by factor analysis of adipose tissue fatty acid composition in a free-living population of middle-aged American men. American Journal of Clinical Nutrition 44, 220-231.

Beynen, A. C. \& Katan, M. B. (1985). Effects of egg yolk feeding on the concentration and composition of serum lipoproteins in man. Atherosclerosis 54, 157-166.

Beynen, A. C., Katan, M. B. \& Van Zutphen, L. F. M. (1986). Individual differences in the cholesterolemic response to change in diet. In Lipid Metabolism and its Pathology, IV International Colloquium pp. $169-174$ [M. J. Halpern, editor]. Amsterdam: Excerpta Medica.

Beynen, A. C., Katan, M. B. \& Van Zutphen, L. F. M. (1987). Hypo- and hyperresponders: individual differences in the response of serum cholesterol concentration to changes in diet. Advances in Lipid Research 22, $115-171$.

Bingham, S. A. (1987). The dietary assessment of individuals: methods, accuracy, new techniques and recommendations. Nutrition Abstracts and Reviews A 57, 705-742.

Blackburn, H. (1987). Epidemiologic evidence for the causes and prevention of atherosclerosis. In Hypercholesterolaemia and Atherosclerosis. Pathogenesis and Prevention, pp. 53-98 [D. J. Steinberg and J. M. Olefsky, editors]. New York: Churchill Livingstone.

Blaton, V., De Buyzere, M., Declercq, B., Pracetyo, A., Vanderkelen, G., Delanghe, J. \& Spincemaille, J. (1984). Effect of polyunsaturated isocaloric fat diets on plasma lipids, apolipoproteins and fatty acids. Atherosclerosis 53, 9-20.

Boberg, M., Vessby, B. \& Selinus, I. (1986). Effects of dietary supplementation with $n-6$ and $n-3$ long-chain polyunsaturated fatty acids on serum lipoproteins and platelet function in hypertriglyceridaemic patients. Acta Medica Scandinavica 220, 153-160.

Bochenek, W. \& Rodgers, J. B. (1978). Effects of saturated and unsaturated fats given with and without dietary cholesterol on hepatic cholesterol synthesis and hepatic lipid metabolism. Biochimica et Biophysica Acta 528. I-16.

Bonanome, A. \& Grundy, S. M. (1988). Effect of dietary stearic acid on plasma cholesterol and lipoprotein levels. New England Journal of Medicine 318, $1244-1248$.

Bronsgeest-Schoute, D. C., Hautvast, J. G. A. J. \& Hermus, R. J. J. (1979a). Dependence of the effects of dietary cholesterol and experimental conditions on serum lipids in man. I. Effects of dietary cholesterol in a linoleic acid-rich diet. American Journal of Clinical Nutrition 32, 2183-2187.

Bronsgeest-Schoute, D. C., Hermus, R. J. J., Dallinga-Thie, G. M. \& Hautvast, J. G. A. J. (1979 b). Dependence of the effects of dietary cholesterol and experimental conditions on serum lipids in man. II. Effects of dietary cholesterol in a linoleic acid-poor diet. American Journal of Clinical Nutrition 32, 2188-2192.

Brown, M. S. \& Goldstein, J. L. (1983). Lipoprotein metabolism in the macrophage: implications for cholesterol deposition in atherosclerosis. Annual Review of Biochemistry 52, 223-261.

Brown, W. V. \& Ginsberg, H. (1987). Classification and diagnosis of the hyperlipidaemias. In Hypercholesterolaemia and Atherosclerosis. Pathogenesis and Prevention, pp. 143-168 [D. Steinberg and J. M. Olefsky, editors]. New York: Churchill Livingstone.

Brussaard, J. H., Dallinga-Thie, G., Groot, P. H. E. \& Katan, M. B. (1980). Effects of amount and type of dietary fat on serum lipids, lipoproteins and apolipoproteins in man-a controlled 8-week trial. Atherosclerosis 36, 515-527.

Burger, W. C., Qureshi, A. A., Prentice, N. \& Elson, C. E. (1982). Effects of different fractions of the barley kernel on the hepatic lipid metabolism of chickens. Lipids 17, 956-963.

Buzzard, I. M., McRoberts, M. R., Driscoll, D. L. \& Bowering, J. (1982). Effect of dietary eggs and ascorbic acid on plasma lipid and lipoprotein cholesterol levels in healthy young men. American Journal of Clinical Nutrition 36, 94-105.

Carey, M. C., Small, D. M. \& Bliss, C. M. (1983). Lipid digestion and absorption. Annual Review of Physiology $45,651-677$.

Christophe, A., Matthys, F., Geers, R. \& Verdonk, G. (1978). Nutritional studies with randomized butter: cholesterolaemic effects of butter oil and randomized butter oil in man. Archives Internationales de Physiologie et de Biochimie 86, 413-415.

Connor, W. E., Hodges, R. E. \& Bleiler, R. E. (1961). Effect of dietary cholesterol upon serum lipids in man. Journal of Laboratory and Clinical Medicine 57, 331-342. 
Connor, W. E., Lin, D. S. \& Harris, W. B. (1981). A comparison of dietary polyunsaturated $\omega-6$ fatty acids in humans: effects upon plasma lipids, lipoprotein and sterol balance. Arteriosclerosis 1, 363a.

Connor, W. E., Stone, D. B. \& Hodges, R. E. (1964). The interrelated effects of dietary cholesterol and fat upon human serum lipid levels. Journal of Clinical Investigation 43, 1691-1696.

Department of Health and Social Security (1984). Diet and cardiovascular disease: Committee on Medical Aspects of Food Policy. Report on Health and Social Subjects no. 28. London: H.M. Stationery Office.

Eggen, D. A. (1976). Cholesterol metabolism in groups of rhesus monkeys with high or low reponse of serum cholesterol to an atherogenic diet. Journal of Lipid Research 17, 663-673.

Erickson, B. A., Coots, R. H., Mattson, F. H. \& Kligman, A. M. (1964). The effect of partial hydrogenation of dietary fats, of the ratio of polyunsaturated to saturated fatty acids, and of dietary cholesterol upon plasma lipids in man. Journal of Clinical Investigation 43, 2017-2025.

Fehily, A. M., Yarnell, J. W. G., Bolton, C. H. \& Butland, B. K. (1988). Dietary determinants of plasma lipids and lipoproteins : the Caerphilly Study. European Journal of Clinical Nutrition 42, 405-413.

Flynn, M. A., Nolph, G. B., Flynn, T. C., Kahrs, R. \& Krause, G. (1979). Effect of dietary egg on human serum cholesterol and triglycerides. American Journal of Clinical Nutrition 32, 1051-1057.

Food and Agriculture Organization (1986). FAO production yearbook 1985. Rome: FAO.

Freckleton, A. M. (1986). The impact of a supermarket education programme. Food Policy Research Unit Report. Bradford: University of Bradford.

Frick, M. H., Elo, O., Haapa, K., Heinonen, O. P., Heinsalmi, P., Helo, P., Huttunen, J. K., Kaitaniemi, P., Koskinen, P., Manninen, V., Maempaa, H., Malkonen, M., Manttari, M., Norola, S., Pasternack, A., Pikkarainen, J., Romo, M., Sjoblom, T. \& Nikkila, E. A. (1987). Helsinki Heart Study: Primary prevention trial with gemfibrozil in middle-aged men with dyslipidaemia. New England Journal of Medicine 317, $1237-1245$.

Galton, D. J. (1985). Molecular Genetics of Common Metabolic Diseases. London: Edward Amold.

Gavigan, S. J. P. \& Knight, B. L. (1981). Catabolism of low-density lipoprotein by fibroblasts cultured in medium supplemented with saturated or unsaturated free fatty acids. Biochimica et Biophysica Acta 665, 632-635.

Glueck, C. J. \& Connor, W. E. (1978). Diet-coronary heart disease relationships reconnoitred. American Journal of Clinical Nutrition 31, 727-737.

Goldberg, A. C. \& Schonfeld, G. (1985). Effects of diet on lipoprotein metabolism. Annual Review of Nutrition 5 , $195-212$.

Goldstein, J. L. \& Brown, M. S. (1977). The low density lipoprotein pathway and its relation to atherosclerosis. Annual Review of Biochemistry 46, 897-930.

Goldstein, J. L. \& Brown, M. S. (1984). Progress in understanding the LDL receptor and HMG-CoA reductase, two membrane proteins that regulate the plasma cholesterol. Journal of Lipid Research 25, 1450-1461.

Goodnight, S. H., Harris, W. S., Connor, W. E. \& Illingworth, D. R. (1982). Polyunsaturated fatty acids, hyperlipidemia, and thrombosis. Arteriosclerosis 2, 87-113.

Gordon, T., Fisher, M. \& Rifkind, B. M. (1984). Some difficulties inherent in the interpretation of dietary data from free-living populations. American Journal of Clinical Nutrition 39, 152-156.

Grinstead, G. F. \& Ellefson, R. D. (1988). Heterogeneity of lipoprotein Lp(a) and apolipoprotein (a). Clinical Chemistry 34, 1036-1040.

Groen, J., Tjiong, B. K., Kamminga, C. E. \& Willebrands, A. F. (1952). The influence of nutrition, individuality and some other factors, including various forms of stress, on the serum cholesterol; an experiment of nine months duration in 60 normal human volunteers. Voeding 13, 556-587.

Grundy, S. M. (1983). Absorption and metabolism of dietary cholesterol. Annual Review of Nutrition 3, 71-96.

Grundy, S. M. (1986). Comparison of monounsaturated fatty acids and carbohydrates for lowering plasma cholesterol. New England Journal of Medicine 314, 745-748.

Grundy, S. M., Florentin, L., Nix, D. \& Whelan, M. F. (1988). Comparison of monounsaturated fatty acids and carbohydrates for reducing raised levels of plasma cholesterol in man. American Journal of Clinical Nutrition 47, 965-969.

Gurr, M. I. (1988). Lipid metabolism in man. Proceedings of the Nutrition Society 47, 277-285.

Gurr, M. I. \& James, A. T. (1980). Lipid Biochemistry: An Introduction, 3rd ed. London: Chapman \& Hall.

Harris, W. S., Connor, W. E. \& McMurry, M. P. (1983). The comparative reductions of the plasma lipids and lipoproteins by dietary polyunsaturated fats: salmon oil versus vegetable oils. Metabolism 32, $179-184$.

Havel, R. J. (1980). Lipoprotein biosynthesis and metabolism. Annals of the New York Academy of Sciences 348, 16-27.

Havel, R. J. (1986). Functional activities of hepatic lipoprotein receptors. Annual Review of Physiology 48, $119-134$.

Hegsted, D. M., Andrus, S. B., Gotsis, A. \& Portman, O. W. (1957). The quantitative effects of cholesterol, cholic acid and type of fat on serum cholesterol and vascular sudanophilia in the rat. Journal of Nutrition 63, 273-288.

Hegsted, D. M., McGandy, R. B., Myers, M. L. \& Stare, F. J. (1965). Quantitative effects of dietary fat on serum cholesterol in man. American Journal of Clinical Nutrition 17, 281-295.

Hirsch, J., Farquar, J. W., Ahrens, E. H., Peterson, M. L. \& Stoffel, W. (1960). Studies of adipose tissue in man: a microtechnique for sampling and analysis. American Journal of Clinical Nutrition 8, 499-511.

Hjermann, I., Velve-Byre, K., Holme, I. \& Leren, P. (1981). Effect of diet and smoking intervention on the 
incidence of CHD: report from the Oslo Study Group of a randomized trial in healthy men. Lancet ii, 1303-1310.

Horrobin, D. F. \& Manku, M. S. (1983). How do polyunsaturated fatty acids lower plasma cholesterol levels? Lipids 18, 558-562.

Hostmark, A. T., Spydevold, O. \& Eilertsen, E. (1980). Plasma lipid concentration and liver output of lipoproteins in rats fed coconut fat or sunflower oil. Artery 7, 367-383.

Illingworth, D. R., Harris, W. S. \& Connor, W. E. (1984). Inhibition of low density lipoprotein synthesis by dietary omega-3 fatty acids in humans. Arteriosclerosis 4, 270-275.

Jackson, R. L., Kashyap, M. L., Barnhart, R. L., Allen, C., Hogg, E. \& Glueck, C. J. (1984). Influence of polyunsaturated and saturated fats on plasma lipids and lipoproteins in man. American Journal of Clinical Nutrition 39, 589-597.

Jackson, R. L., Taunton, O. D., Morrisett, J. D. \& Gotto, A. M. (1978). The role of dietary polyunsaturated fat in lowering blood cholesterol in man. Circulation Research 42, 447-453.

Jacobs, D. R., Anderson, J. T., Hannan, P., Keys, A. \& Blackburn, H. (1983). Variability in individual serum cholesterol response to change in diet. Arteriosclerosis 3, 349-356.

Janetschek, P., Weisweiler, P., Heinemann, V. \& Schwandt, P. (1983). Effect of a fat-modified diet on the lecithincholesterol acyl transfer rate. In Diabetes, Ohesity and Hyperlipidemias II, pp. I09 II3. [G. Crepa!di, P. J. Lefebvre and D. J. Galton, editors]. New York: Academic Press.

Johnson, F. L., St Clair, R. W. \& Rudel, L. L. (1985). Effects of the degree of saturation of dietary fat on the hepatic production of lipoproteins in the African green monkey. Journal of Lipid Research 26, 403-417.

Kaneda, T. \& Alfin-Slater, R. B. (1963). A comparison of the effects of the polyunsaturated fatty acids of cuttlefish liver oil and cottonseed oil on cholesterol metabolism. Journal of the American Oil Chemists' Society 40 , $336-338$.

Katan, M. B. \& Beynen, A. C. (1986). Hyperresponsiveness of plasma cholesterol to dietary cholesterol and dietary fatty acids in inbred rabbit strains and in man. Progress in Lipid Research 25, 491-493.

Katan, M. B., Van Staveren, W. A., Deurenberg, P., Barendse-van Leeuwen, J., Germing-Nouwen, C., Soffers, A., Berkell, J. \& Beynen, A. C. (1986). Linoleic and trans-unsaturated fatty acid content of adipose tissue biopsies as objective indicators of the dietary habits of individuals. Progress in Lipid Research 25, $193-195$.

Keys, A. (1970). Coronary heart disease in seven countries. Circulation 41, Suppl. 1.

Keys, A. (1988). Diet and blood cholesterol in population surveys-lessons from analysis of the data from a major survey in Israel. American Journal of Clinical Nutrition 48, 1161-1165.

Keys, A., Anderson, J. T. \& Grande, F. (1957). Prediction of serum-cholesterol responses of man to changes in fats in the diet. Lancet ii, 959-966.

Keys, A., Anderson, J. T. \& Grande, F. (1965). Serum cholesterol response to changes in the diet. IV. Particular saturated fatty acids in the diet. Metabolism 14, 776-787.

Kingsbury, K. J., Aylott, C., Morgan, D. M. \& Emmerson, R. (1961). Effects of ethyl arachidonate, cod-liver oil, and corn oil on the plasma cholesterol level. A comparison in normal volunteers. Lancet $\mathbf{i}, 739-741$.

Kinsell, L. W., Partridge, J., Boling, L., Margen, S. \& Michaels, G. (1952). Diet and serum lipids. Journal of Clinical Endocrinology 12, 909-913.

Kohlmeier, M., Stricker, G. \& Schlierf, G. (1985). Influences of 'normal' and 'prudent' diets on biliary and serum lipids in healthy women. American Journal of Clinical Nutrition 42, 1201-1205.

Kritchevsky, D. (1980). Age-related changes in lipid metabolism. Proceedings of the Society for Experimental Biology and Medicine 165, 193-199.

Kritchevsky, D., Tepper, S. A., Bises, G. \& Klurfeld, D. M. (1982). Experimental atherosclerosis in rabbits fed cholesterol-free diets. Part 10: Cocoa-butter and palm oil. Atherosclerosis 41, 279-284.

Kritchevsky, D., Tepper, S. A., Vesselinovitch, D. \& Wissler, R. W. (1973). Cholesterol vehicle in experimental atherosclerosis. 13. Randomized peanut oil. Atherosclerosis 17, 225-243.

Kwiterovich, P. O., Bachorik, P. S., Franklin, F. A., Margolis, S., Georgopoulos, L., Teng, B. \& Sniderman, A. D. (1985). Effect of dietary treatment on the plasma levels of lipids, lipoprotein cholesterol and LDL B protein in children with type II hyperlipoproteinemia. In Detection and Treatment of Lipid and Lipoprotein Disorders of Childhood, pp. 123-137 [K. Widhalm and H. K. Naito, editors]. New York: Alan R. Liss.

McGandy, R. B. \& Hegsted, D. M. (1975). Quantitative effects of dietary fat and cholesterol on serum cholesterol in man. In The Role of Fats in Human Nutrition, pp. 211-230 [A. J. Vergroesen, editor]. London: Academic Press.

McGandy, R. B., Hegsted, D. M. \& Myers, M. L. (1970). Use of semi-synthetic fats in determining effects of specific dietary fatty acids on serum lipids in man. American Journal of Clinical Nutrition 23, $1288-1298$.

McGill, H. C., McMahan, A. \& Wene, J. D. (1981). Unresolved problems in the diet-heart issue. Arteriosclerosis 1, 164-176.

McMurchie, E. J. (1988). Dietary lipids and the regulation of membrane fluidity and function. In Physiological Regulation of Membrane Fluidity, pp. 189-237. New York: Alan R. Liss.

McNamara, D. J. (1987). Effects of fat-modified diets on cholesterol and lipoprotein metabolism. Annual Review of Nutrition 7, 273-290.

Mahley, R. W. (1978). Alterations in plasma lipoproteins induced by cholesterol feeding in animals including man. 
In Disturbances in Lipid and Lipoprotein Metabolism, pp. 181-197. [J. M. Dietschy, A. M. Gotto and J. A. Ontko, editors]. Bethesda, MD: American Physiological Society.

Mahley, R. W., Innerarity, T. L., Bersot, T. P., Lipsom, A. \& Margolis, S. (1978). Alterations in human high density lipoproteins with or without increased plasma cholesterol induced by diets high in cholesterol. Lancet ii, 807-809.

Marr, J. W. (1981). Individual variation in dietary intake. In Preventive Nutrition and Society, pp. $77-83$ [M. R. Turner, editor]. London: Academic Press.

Mattson, F. H. \& Grundy, S. M. (1985). Comparisons of the effects of dietary saturated, monounsaturated and polyunsaturated fatty acids on plasma lipids and lipoproteins in man. Journal of Lipid Research 26, $194-202$.

Mensink, R. P. \& Katan, M. B. (1987). Effects of monounsaturated fatty acids versus complex carbohydrates on HDL in healthy men and women. Lancet $i, 122-125$.

Ministry of Agriculture, Fisheries and Food (1987). Household Food Consumption and Expenditure. London: H.M. Stationery Office.

Mistry, P., Miller, N. E., Laker, M., Hazzard, W. R. \& Lewis, B. (1981). Individual variation in the effects of dietary cholesterol on plasma lipoproteins and cellular cholesterol homeostasis in man. Studies of LDL receptor activity and 3-hydroxy-3-methylglutaryl-CoA reductase activity in blood mononuclear cells. Journal of Clinical Investigation 67, 493-502.

Moore, J. H. \& Williams, D. L. (1966). The effect of an atherogenic diet on plasma lipid composition and aortic atherosis in two strains of New Zealand White rabbit. British Journal of Nutrition 20, 571-580.

Mulvihill, B. J. \& Walker, B. L. (1984). Dietary fatty acids-cholesterol interaction and serum cholesterol in the hypercholesterolemic mouse. Nutrition Research 4, 611-619.

Myher, J. J., Marai, L., Kuksis, A. \& Kritchevsky, D. (1977). Acylglycerol structure of peanut oils of different atherogenic potential. Lipids 12, 775-785.

Needleman, P., Turk, J., Jakschik, B. A., Morrison, A. R. \& Lefkowith, J. B. (1986), Arachidonic acid metabolism. Annual Review of Biochemistry 55, 69-102.

Nestel, P. J., Connor. W. E., Reardon, M. F., Connor, S., Wong, S. \& Boston, R. (1984). Suppression by diets rich in fish oil of very low density lipoprotein production in man. Journal of Clinical Investigation 74, 82-89.

Nestel, P. J., Tada, N., Billington, T., Huff, M. \& Fidge, N. (1982). Changes in very low density lipoproteins with cholesterol loading in Man. Metabolism 31, 398-405.

Nichols, A. B., Ravenscroft, C., Lamphiear, D. E. \& Ostrander, L. D. (1976). Daily nutritional intake and serum lipid levels. The Tecumseh study. American Journal of Clinical Nutrition 29, 1384-1392.

Oh, S. Y. \& Monaco, P. A. (1985). Effect of dietary cholesterol and degree of fat unsaturation on plasma lipid levels, lipoprotein composition and fecal steroid excretion in normal young adult men. American Journal of Clinical Nutrition 42, 399-413.

O'Hara-May, J. (1987). Nutritionists' views on nutrition. Human Nutrition: Applied Nutrition 41 A, $265-284$.

Paul, R., Ramesha, C. S. \& Ganguly, J. (1980). On the mechanism of hypocholesterolemic effects of polyunsaturated lipids. Advances in Lipid Research 17, 155-171.

Pownall, H. J., Shepherd, J., Mantulin, W. W., Sklar, L. A. \& Gotto, A. M. (1980). Effect of saturated and polyunsaturated fat diets on the composition and structure of human low density lipoproteins. Atherosclerosis 36, 299-314.

Prior, I. A., Davidson, F., Salmond, C. E. \& Czochanska, Z. (1981). Cholesterol, coconuts and diet on Polynesian atolls, a natural experiment: the Pukapuka and Tokelau Island studies. American Journal of Clinical Nutrition 34, 1552-1561.

Richard, M. J., Julius, A. D. \& Wiggers, K. D. (1983). Effects of dietary protein and fat on cholesterol deposition and body composition of pigs. Nutrition Reports International 28, 973-981.

Richard, M. J., Serbus, D. C., Beitz, D. C. \& Jacobson, N. L. (1982). Effect of type and amount of dietary fat on the concentration of cholesterol in blood plasma and tissues of rabbits. Nutrition Research 2, 175-183.

Richard, M. J., Stewart, J. W., Heeg, T. R., Wiggers, K. D. \& Jacobson, N. L. (1980). Blood plasma lipoprotein and tissue cholesterol of calves fed soybean oil, corn oil, vegetable shortening or tallow. Atherosclerosis 37 . 513-520.

Roberts, S. L., McMurry, M. P. \& Connor, W. E. (1981). Does egg feeding (i.e., dietary cholesterol) affect plasma cholesterol levels in humans? The results of a double-blind study. American Journal of Clinical Nutrition 34, 2092-2099.

Roheim, P. S. (1986). Atherosclerosis and lipoprotein metabolism: role of reverse cholesterol transport. American Journal of Cardiology 57, 3C-10C.

Sacks, F. M., Handysides, G. H., Marais, G. E., Rosner, B. \& Kass, E. H. (1986). Effects of a low-fat diet on plasma lipoprotein levels. Archives of Internal Medicine 146, 1573-1577.

Sacks, F. M.. Ornish, D., Rosner, B., McLanahan, S., Castelli, W. P. \& Kass, E. H. (1985). Plasma lipoprotein levels in vegetarians. The effect of ingestion of fats from dairy products. Journal of the American Medical Association 254, 1337-1341.

Sacks, F. M., Salazar, J., Miller, L., Foster, J. M., Sutherland, M., Samonds, K. W., Albers, J. J. \& Kass, E. H. (1984). Ingestion of egg raises plasma low density lipoproteins in free-living subjects. Lancet $\mathbf{i}, 647-649$.

Sanders, T. A. B. (1988). Essential and trans-fatty acids in nutrition. Nutrition Research Reviews 1, 57-78. 
Schectman, G., Kaul, S. \& Kissebah, A. M. (1988). Effect of fish oil concentrate on lipoprotein composition in NIDDM. Diabetes 37, 1567-1573.

Shekelle, R. B., Shyrock, A. M., Paul, O., Lepper, M., Stamler, J., Liu, S. \& Raynor, W. J. (1981). Diet, serum cholesterol and death from coronary heart disease. The Western Electric Study. New England Journal of Medicine 304, 65-70.

Shepherd, J., Packard, C. J., Grundy, S. M., Yeshurun, D., Gotto, A. M. \& Taunton, O. D. (1980). Effects of saturated and polyunsaturated fat diets on the chemical composition and metabolism of low density lipoproteins in man. Journal of Lipid Research 21, 91-99.

Simons, L. A., Hickie, J. B. \& Balasubramaniam, S. (1985). On the effects of dietary n-3 fatty acids (Maxepa) on plasma lipids and lipoproteins in patients with hyperlipidaemia. Atherosclerosis 54, 75-88.

Stein, E. A., Mendelsohn, D., Fleming, M., Barnard, G. D., Carter, K. J., Toit, P. S., Hansen, J. D. L. \& Bersohn, I. (1975). Lowering of plasma cholesterol levels in free-living adolescent males; use of natural and synthetic polyunsaturated foods to provide balanced fat diets. American Journal of Clinical Nutrition 28, 1204-1216.

Stern, M. P. \& Haffner, S. M. (1986). Body fat distribution and hyperinsulinaemia as risk factors for diabetes and cardiovascular disease. Arteriosclerosis 6, 123-130.

Tall, A. R. (1986). Plasma lipid transfer proteins. Journal of Lipid Research 27, 361-367.

Tamamoto, I., Sugano, M. \& Wada, M. (1971). Hypocholesterolaemic effect of animal and plant fats in rats. Atherosclerosis 13, 171-184.

Tso, P. (1985). Gastrointestinal digestion and absorption of lipid. Advances in Lipid Research 21, 143-186.

Ueshima, H., lida, M., Shimamoto, T., Konishi, M., Tanigaki, M., Dui, M., Nakanishi, N., Takayama, Y., Ozawa, H. \& Komachi, Y. (1982). Dietary intake and serum total cholesterol level. Their relationship to different lifestyles in several Japanese populations. Circulation 66, 519-526.

Vance, D. E. \& Vance, J. E. (editors) (1985). Biochemistry of Lipids and Membranes. Menlo Park, CA: Benjamin/Cummings Publishing Co.

Van Zutphen, L. F. M. \& Fox, R. R. (1977). Strain differences in response to dietary cholesterol by Jax rabbits: correlation with esterase patterns. Atherosclerosis 28, 435-446.

Wallace, R. B. \& Anderson, R. A. (1987). Blood lipids, lipid rejated measures and the risk of atherosclerotic cardiovascular disease. Epidemiological Reviews 9, 95-119.

Watts, G. F., Ahmed, W., Quiney, J., Houlston, R., Jackson, P., Iles, C. \& Lewis, B. (1988). Effective lipid lowering diets including lean meat. British Medical Journal 296, 235-237.

Weisweiler, P., Janetschek, P. \& Schwandt, P. (1985). Influence of polyunsaturated fats and fat restriction on serum lipoproteins in humans. Metabolism 34, 83-87.

Wiggers, K. D., Richard, M. J., Stewart, J. W., Jacobson, N. L. \& Berger, P. J. (1977a). Type and amount of dietary fat affect relative concentration of cholesterol in blood and other tissues of rats. Atherosclerosis 27, 27-34.

Wiggers, K. D., Richard, M. J., Stewart, J. W., Jacobson, N. L. \& Berger, P. J. (1977b). Type and amount of dietary fat affect relative concentration of cholesterol in blood and other tissues of calves. Lipids 12, 586-590.

Williams, P. T., Kraus, R. M., Kindel-Joyce, S., Dreon, D., Vranizan, K. M. \& Wood, P. D. (1986). Relationship of dietary fat, protein, cholesterol and fiber intake to atherogenic lipoproteins in men. American Journal of Clinical Nutrition 44, 788-797. 